\title{
$\mathrm{Wi}-\mathrm{Fi}$ 기반 차량 네트워크에서의 인터넷 처리율 분석
}

\author{
김 원 중 + 김 영 현 $^{++} \cdot$ 윤 주 상 ${ }^{+++} \cdot$ 백 상 헌 $^{++++}$
}

요 약

최근 무선 통신의 발달과 무선 접속 기기의 등장으로 인하여 언제, 어디서든 인터넷을 접속하여 다양한 응용 프로그램을 사용할 수 있게 되 었다. 특히, 차량 네트워크의 발달로 이동 중인 차량에서도 인터넷 접속이 가능하게 되었다. 또한, 차량 네트워크와 관련된 다양한 연구들이 활 발히 진행되고 있다. 본 논문에서는 실제로 쓰이는 다양한 차량 네트워크의 구조를 살펴보고, 각 구조에서 차량 내에서의 $\mathrm{Wi}-\mathrm{Fi}$ 와 외부의 네트 워크를 종합적으로 고려하여 성능 측정을 하였다. 성능 측정 결과를 통해서 현재 사용되고 있는 차량 네트워크의 유용성을 판단하였다.

키워드 : 차량 네트워크, 인터넷, 처리율 측정, 자원 관리

\section{Throughput Analysis in Vehicular Wi-Fi Networks}

\author{
Wonjung $\mathrm{Kim}^{+} \cdot$ Younghyun $\mathrm{Kim}^{++} \cdot$ JooSang Youn ${ }^{+++} \cdot$ Sangheon Pack ${ }^{++++}$
}

\begin{abstract}
Due to advances in wireless communications and portable terminals, any-time, any-where, and any-device Internet access is possible. In particular, Internet access in moving vehicles is an emerging and challenging issue. Even though a variety studies have been conduced for vehicular networks, little attention is paid to vehicular Wi-Fi networks where a Wi-Fi access point (AP) is installed at the vehicle and the AP is connected to an external base station (BS). In this paper, we conduct a measurement study on the uplink and downlink throughput for Internet access in vehicular Wi-Fi networks. We consider diverse network environments: high-speed train, car, and subway. Measurement results demonstrate that current Internet access in vehicular Wi-Fi networks are not satisfactory for interactive multimedia applications. Therefore, in-depth study on resource management in vehicular Wi-Fi networks is strongly required.
\end{abstract}

Keywords : Vehicular Wi-Fi networks, Internet, Throughput Measurement, Resource Management

\section{1. 서 론}

무선 통신기술의 발달로 인해 이동 중인 상황에서도 다양 한 기기들을 이용하여 인터넷 접속이 가능하게 되었고, 최 근 들어 스마트폰과 노트북의 보급이 늘어남에 따라 무선 인터넷 접속을 이용하는 사용자의 수가 급격히 증가하였다. 특히, $\mathrm{Wi}-\mathrm{Fi}$ (Wireless Fidelity)는 무선접속장치 (Access

※ 본 연구는 서울특별시의 서울 벨 연구소 사업(서울시 산학협력사업(WR 080951)) 및 2009년 정부(교육과학기술부)의 재원으로 한국연구재단의 지원을 받아 수행된 연구임(과제번호: 2009-0064397).

※ 본 논문의 일부는 IEEE VTC 2010 Fall에서 발표되었음

† 준 회 원 : 고려대학교 전기전자전파공학부 석사과정

†† 춘 회 원: 고려대학교 전기전자전파공학부 박사과정

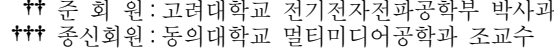

꿰 종신회원: 고려대학교 전기전자전파공학부 조교수(교신저자) 논문접수: 2010년 8월 25일

수 정 일: 1 차 2010년 10월 27일, 2 차 2010년 11월 24일

심사완료 : 2010 년 11월 24일
Point: $\mathrm{AP}$ )가 설치된 일정 거리 안에서 저렴한 가격으로 초 고속 인터넷을 사용할 수 있게 하는 무선 접속 기술이다. 이를 이용해 다양한 교통수단(자동차, 버스, 지하철, KTX 등) 안에서도 무선 인터넷 접속이 가능하나, $\mathrm{Wi}-\mathrm{Fi}$ 가 제공 하는 서비스 지역은 매우 제한적이기 때문에, 빠르게 이동 하는 차량 내에서 $\mathrm{Wi}-\mathrm{Fi}$ 를 이용하는 것은 적합하지 않다. 따라서 차량 내의 노드들에게 인터넷 서비스를 제공하기 위 해 WLAN (Wireless Local Area Network)과 WWAN (Wireless Wide Area Network)을 결합한 새로운 구조가 제 안되었다. 차량에는 $\mathrm{AP}$ 가 설치되어, 차량 내의 사용자들과 $\mathrm{AP}$ 는 $\mathrm{Wi}-\mathrm{Fi}$ 를 이용하여 무선 접속을 유지한다. 그리고 차 랑 내 노드에게 인터넷 접속을 제공하기 위해, $\mathrm{AP}$ 는 HSDPA (High Speed Downlink Packet Access)나 WiBro (Wireless Broadband)와 같은 WWAN을 이용하여 기지국 
(base station: BS)과 접속한다. 이 구조가 현재 사용 가능한 대표적인 차량 네트워크 구조이다.

우리나라에서는 2008년 4월부터 HSDPA과 $\mathrm{Wi}-\mathrm{Fi}$ 를 결합 한 무선 인터넷 서비스를 $\mathrm{KTX}$ 에서 제공하고 있다. 또한 2009년 4월, $\mathrm{WiBro}$ 와 $\mathrm{Wi}-\mathrm{Fi}$ 접속 기능을 제공하는 휴대형 무선공유기 egg가 발매되면서, 언제 어디서든지 (차량 내에 서도) $\mathrm{Wi}-\mathrm{Fi}$ 기기를 이용하여, 사용자는 인터넷에 접근할 수 있게 되었다. 뿐만 아니라 2010년 5월부터는 WCDMA 휴대전화 신호를 $\mathrm{Wi}-\mathrm{Fi}$ 신호로 전환해 주는 휴대용 공유기 '단비'가 출시되어 이를 이용한 차량 네트워크의 서비스 활 용이 기대된다. 그리고 최근 출시된 아이폰, 갤럭시 $\mathrm{S}$ 등의 스마트폰에서도, 중계기 역할을 담당하는 테더링 기능이 제 공된다. 이렇게 WWAN-WLAN의 결합된 구조는 현재 활발 히 활용되고 있다.

그러나 차량 네트워크에서 $\mathrm{Wi}-\mathrm{Fi}$ 를 이용한 인터넷 접속 에 관한 연구는 초기 단계이고, 실제적인 처리율에 대한 측 정 및 분석이 전무한 상태이다. 현재 성능분석 분야에 대한 연구는 차량 네트워크의 일반적인 WWAN과 WLAN이 결 합된 구조가 아닌 차량에서 $\mathrm{Wi}-\mathrm{Fi}$ 만을 이용해 인터넷에 접 속하는 연구가 대부분이다[1][2].

본 논문은 차량 네트워크의 대표적인 구조인 WWAN과 $\mathrm{WLAN}$ 이 결합된 구조 [3]를 이용하여 차량 네트워크의 처 리율을 측정 및 분석한다. 첫 번째는 $\mathrm{KTX}$ 에서 제공하는 $\mathrm{HSDPA}$ 와 $\mathrm{Wi}-\mathrm{Fi}$ 구조, 두 번째는 지하철에서 스마트폰의 테더링 기능을 이용한 HSPA (High Speed Packet Access) 신호를 $\mathrm{Wi}-\mathrm{Fi}$ 신호로 변환시키는 구조의 성능 분석을 한다. 마지막으로, 휴대형 무선공유기 egg를 이용하여 WiBro와 $\mathrm{Wi}-\mathrm{Fi}$ 가 결합된 구조를 가지고 지하철과 자동차에서 각각 데이터 처리율에 대한 성능분석을 한다. 성능 측정은 일반 적으로 널리 사용되는 측정 도구를 이용하여 업링크와 다운 링크의 처리율을 측정하였고, 현재 서비스되고 있는 차량 네트워크의 유용성을 판단하고 서비스 품질을 확인하였다.

본 논문의 구성은 다음과 같다. 2장에서는 차량 네트워크 의 인터넷 접속의 처리율의 측정 방법 및 환경에 대해 서술 하고, 3 장에 측정결과와 이에 대한 분석을 한다. 그리고 4장 에서 관련 연구를 소개하고, 마지막으로 5장에서 본 논문의 결론 및 향후 연구 과제를 서술한다.

\section{2. 성능분석 환경}

차량 네트워크의 성능 분석을 위하여 우리는 세 가지 네 트워크 구조에 대한 처리율을 측정하였다. 첫 번째 구조는 (그림 1)과 같이, $\mathrm{KTX}$ 에서 사용되는 $\mathrm{HSDPA}$ 와 $\mathrm{Wi}-\mathrm{Fi}$ 가 결 합한 형태이다. $\mathrm{HSDPA}$ 는 고속하향패킷접속을 통하여 $\mathrm{WCDMA}$ 나 CDMA보다 빠른 속도로 데이터를 받을 수 있 는 3.5세대 이동통신방식 기술이다. KTX 무선 네트워크에
서 외부 기지국은 $\mathrm{HSDPA}$ 무선 접속 기술을 이용하여 $\mathrm{AP}$ 와 접속하고, $\mathrm{AP}$ 와 단말은 $\mathrm{Wi}-\mathrm{Fi}$ 를 이용하여 접속을 유지하여, 최종적으로 차량 내의 단말은 인터넷에 엑세스할 수 있다. 두 번째는, (그림 2)에서 볼 수 있듯이, 테더링 기능을 제공 하는 스마트폰의 응용 프로그램을 이용한 HSPA-Wi-Fi 구 조다. 이것은 지하철에서 처리율을 측정하였고, 사용된 어플 리케이션은 윈도우모바일 상의 WMwifirouter이다[4]. 테더링 이란 스마트폰 자체가 무선 모뎀 역할 기능을 하는 것으로, $\mathrm{USB}$ 와 블루투스(Bluetooth), Wi-Fi 등의 통신 기술을 이용 하여 아이팟, 노트북과 같은 IT 기기들에게 무선인터넷 접속 을 제공하는 기능이다. 테더링 기능은 간단히 어플리케이션 을 스마트폰에 설치하는 것으로 사용할 수 있으며, 최근에는 안드로이드 2.2에서 처럼 $\mathrm{OS}$ 에서 기본적으로 지원해주는 기 능이다. 마지막으로, 휴대형 무선공유기 egg를 사용하여, KT 에서 제공하는 $\mathrm{WiBro}$ 신호를 $\mathrm{Wi}-\mathrm{Fi}$ 신호로 변환시켜 무선 인터넷을 사용할 수 있는 구조에 대해, 자동차와 지하철에서 각각 데이터 처리율을 측정하였다. $\mathrm{WiBro}$ 는 시속 $100 \mathrm{Km}$ 의 속도로 이동 중에서도 사용이 가능하며 송수신 거리가 $\mathrm{Wi}-\mathrm{Fi}$ 보다 넓지만 $\mathrm{HSDPA}$ 와는 달리, 수도권 및 일부 지역 에서만 사용가능하다. $\mathrm{Egg}$ 를 사용한 구조는 (그림 3)과 같다.

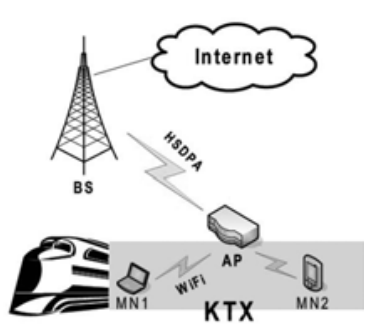

(그림 1) KTX에서 HSDPA $\mathrm{Wi}-\mathrm{Fi}$ 네트워크 구조

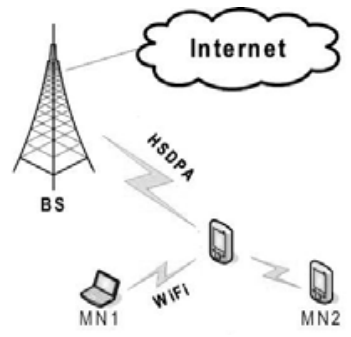

(그림 2) 스마트폰을 이용한 HSDPA - Wi-Fi 네트워크 구조

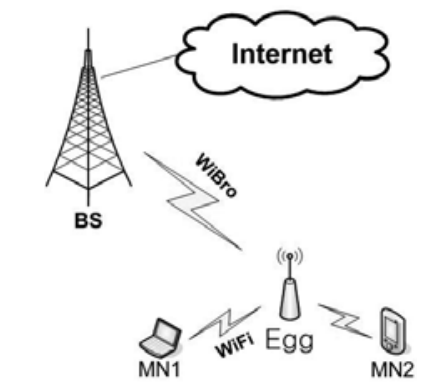

(그림 3) WiBro - Wi-Fi 네트워크 구조

위의 세 가지 네트워크 구조에서 데이터 처리율을 측정하 기 위해, 우리는 한국정보사회진흥원에서 제공하는 인터넷 품질측정 시스템 [5]과 오픈소스로 제공되는 네트워크 측정 도구인 Iperf [6]를 사용하였다. 2008년 4월에 릴리즈 된 Iperf는 네트워크 구간에 있는 2대의 호스트 간 네트워크 성 
능을 측정할 수 있는 도구로서 다양한 종류의 운영체제(윈 도우, 리눅스, $\mathrm{MacOS}$, 솔라리스 등)을 지원한다. 또한 소프 트웨어 설치과정과, 사용방법이 간단하며 $\mathrm{TCP}$ 의 윈도우 크 기, 포트 번호, UDP 대역폭 등의 다양한 파라미터를 조절하 여 네트워크 성능을 측정할 수 있기 때문에 널리 사용되는 측정도구 중 하나이다 $[7,8]$. (그림 4)는 Iperf의 실행화면의 예를 보여준다. 그림에서 볼 수 있듯이, 서버의 IP 주소는 본 연구실의 서버주소인 163.152.60.196이다. 우선, 클라이언 트는 서버에 접속한 후, 일정시간 동안 (다운링크, 업링크 각각 18 초) 서버에 임의의 패킷을 생성, 전송하여, 그 결과 를 화면에 출력한다. 데이터 업로드가 끝나면, 반대로 서버 에서 클라이언트로 데이터가 전송되어 다운링크 처리율이 측정된다. 그러나 $\mathrm{KTX}$ 네트워크의 경우, $\mathrm{AP}$ 에서 동작하는 방화벽으로 인해 Iperf를 사용할 수 없었기 때문에, 한국정 보사회진흥원에서 제공하는 웹 기반의 인터넷 품질측정 시 스템을 활용하였고, (그림 5)는 인터넷 품질측정 시스템 실 행의 예를 보여준다.

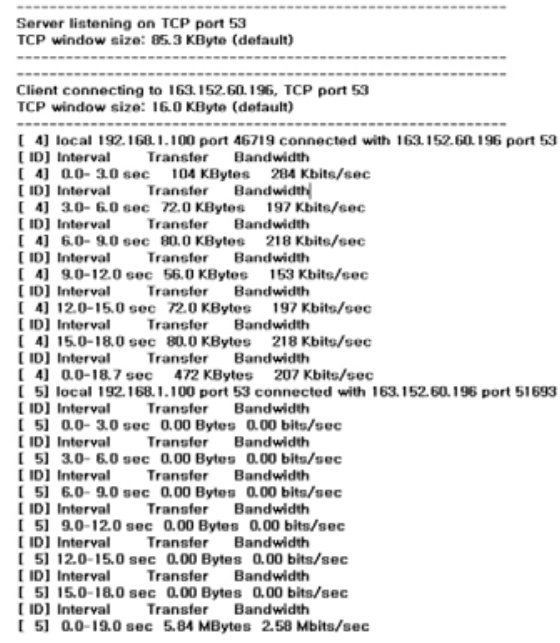

(그림 4) Iperf 실행화면

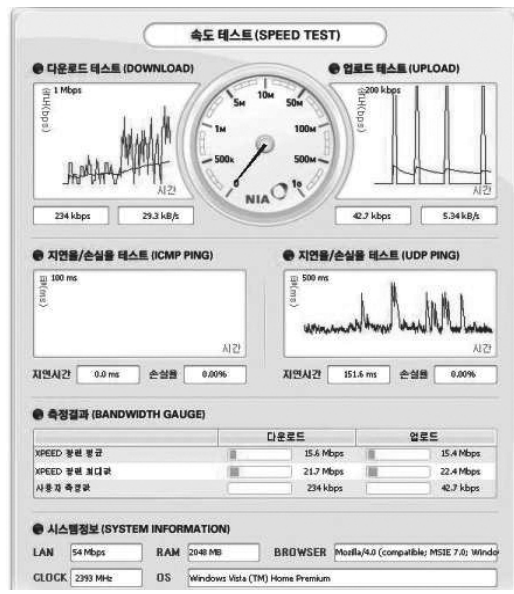

(그림 5) 한국정보사회진흥원 인터넷 품질측정 시스템 실행화면
이처럼 KTX에서는 Iperf를 사용할 수 없어 다른 측정도 구를 사용하였기 때문에, 두 측정 방법 사이의 직접적인 비 교는 어렵다. 하지만, 본 연구는 $\mathrm{KTX}$ 와 지하철 등에서의 인터넷 처리율의 성능 비교가 주목적이 아니라 다양한 토폴 로지 상황에서 현재의 인터넷 서비스의 수준을 가늠하고 향 후 서비스 활성화를 도모하기 위한 것이므로, 이러한 측정 방법에 큰 무리가 없다고 사료된다. 한편 각 도구의 성능 측정 시간은 각각 수 십초이었고, 따라서 실험 시 세션의 핸드오버는 고려하지 않았다.

\section{3. 성능측정 결과}

본 장에서는 $\mathrm{KTX}$, 지하철, 자동차 내에서 측정한 결과에 대해 각각 분석한다. <표 $1>$ 은 성능 측정을 위한 실험환경 을 보여준다. $\mathrm{Egg}$ 와 스마트폰을 이용한 데이터 처리율 실험 은, 실험을 위한 하나의 노드만이 $\mathrm{WLAN}$ 에 접속하여 진행 하였다. 또한 $\mathrm{AP}$ (Egg, 스마트폰)과 노드 사이의 거리는 $1 \mathrm{~m}$ 이내로, 전파경로 손실을 무시할 수 있는 정도였다. 반 면 KTX 무선 인터넷의 경우, 다른 사용자들도 같은 $\mathrm{AP}$ 를 통해 인터넷에 접속할 수 있기 때문에, $\mathrm{Egg}$ 와 스마트폰의 실험보다 큰 채널 간섭 현상이 발생한다. 또한 $\mathrm{KTX}$ 의 $\mathrm{AP}$ 와 노드 사이의 거리는 $\mathrm{Egg}$ 나 스마트폰 실험보다 더 멀기 때문에 더 큰 전파경로 손실이 발생한다. 즉, 전체적으로 $\mathrm{KTX}$ 무선인터넷의 무선 채널 환경은 $\mathrm{Egg}$ 나 스마트폰을 이 용한 무선 채널 환경보다 더 열악한 수준임을 알 수 있다.

〈표 1〉실험 환경

\begin{tabular}{|c|c|}
\hline 측정 도구 & $\begin{array}{c}\text { Iperf [5], } \\
\text { 인터넷 품질 측정 시스템 [6] }\end{array}$ \\
\hline 측정 시간 & 18 초 \\
\hline $\mathrm{WLAN}$ & $802.11 \mathrm{~g}$ \\
\hline $\mathrm{WWAN}$ & $\mathrm{HSDPA}: \mathrm{KTX}$, 지하철 \\
$\mathrm{WiBro}$ : 자동차, 지하철
\end{tabular}

\subsection{HSDPA - Wi-Fi 토폴로지}

$\mathrm{KTX}$ 에서 측정된 평균 다운링크 처리율은 $364 \mathrm{Kbps}$ 이고, 평균 업링크 처리율은 $52.5 \mathrm{Kbps}$ 이다. 구체적인 다운링크와 업링크 처리율 측정결과는 (그림 6)과 같다. (그림 6)에서 볼 수 있듯이, 다운링크 처리율은 $100 \mathrm{Kbps}$ 이하로 측정되기 도 하고 $1000 \mathrm{Kbps}$ 이상의 처리율을 나타내기도 하는 등 측 정 결과들의 변동이 심하다. 또한 업링크 처리율은 대부분 $50 \mathrm{Kbps}$ 로 아주 낮음을 볼 수 있다. 이것은 $\mathrm{KTX}$ 무선 인터 넷 서비스가 높은 다운링크 대역폭과 낮은 업링크 대역폭의 $\mathrm{HSDPA}$ 를 기반으로 하기 때문이다. 따라서 $\mathrm{KTX}$ 에서의 무 선 인터넷 접속 환경은 비실시간성을 가지고 업링크 데이터 
전송량이 적은 기본적인 웹서핑으로는 사용 가능하나, <표 $2>$ 에 제시되어 있는 것처럼 지연시간과 처리율에서 일정 수준 이상의 서비스 품질을 요구하는 $\mathrm{VoIP}$, 실시간/양방향 비디오 스트리밍 서비스에는 적합하지 않음을 알 수 있다. 또한 대용량 파일을 첨부한 $\mathrm{e}-\mathrm{mail}$ 전송이나 $\mathrm{ftp}$ 를 이용한 파일 업로드 같은 서비스 역시, 업로드 데이터 전송량이 많 아 KTX에서는 안정적으로 서비스하기 어려운 것을 확인할 수 있었다.

〈표 2〉실시간 응용 프로그램 서비스 품질 파라미터 [11]

\begin{tabular}{|c|c|c|}
\hline 응용 & 지연시간 & 처리율 \\
\hline VoIP & $100 \mathrm{~ms}$ & 90Kbps \\
\hline $\begin{array}{c}\text { 실시간 비디오 } \\
\text { 스트리밍 }\end{array}$ & $150 \mathrm{~ms}$ & 즈에 따라 다름 \\
\hline 양방향 비디오 & $100 \mathrm{~ms}$ & $\begin{array}{c}\text { 비디오 사이즈의 } 20 \% \\
\text { 이상의 대역폭 필요 }\end{array}$ \\
\hline
\end{tabular}

(그림 7)은 서울 지하철에서 스마트폰의 테더링 응용 프 로그램을 이용하여, $\mathrm{HSPA}$ 신호를 받아 $\mathrm{Wi}-\mathrm{Fi}$ 신호로 변환 하여 인터넷 접속 시 처리율을 측정한 결과이다. 측정 결과, 평균 다운링크 처리율은 $1610 \mathrm{Kbps}$ 이고, 평균 업링크 처리율 은 $372 \mathrm{Kbps}$ 이다. 또한 최대와 최소 다운링크 처리율은 각각 $3790 \mathrm{Kbps}$ 와 $347 \mathrm{Kbps}$ 이고, 최대 업링크 처리율은 $666 \mathrm{Kbps}$, 최소 업링크 처리율은 $24 \mathrm{Kbps}$ 이다. (그림 6)과 비교하여, 스 마트폰 테더링은 다운링크와 업링크의 평균 처리율이 KTX 네트워크보다 높은 것을 확인할 수 있다. 특히 스마트폰을 이용한 테더링의 업링크 처리율은 2009년 10월에 측정한 $\mathrm{KTX}$ 무선인터넷의 업링크보다 높은 것을 볼 수 있는데, 이 는 스마트폰을 이용하여 처리율을 측정했던 2010년 7월에는, HSDPA뿐만 아니라 HSUPA (High Speed Uplink Packet Access) 또한 지원이 되기 때문이다. 실제로 SKT에서는 HSUPA를 2007년 6월에 상용화하여 2010년 5월부터 전국에 $\mathrm{HSPA}$ (HSDPA + HSUPA) 서비스를 제공하고 있다. HSUPA는 고속상향패킷접속을 통해서 데이터 업로드 속도 를 증가시킨 규격이고, HSUPA의 업로드 전송속도는 $\mathrm{HSDPA}$ 가 지원하는 $384 \mathrm{Kbps}$ 보다 15 배가량 늘린 최대 $5.8 \mathrm{Mbps}$ 까지 구현할 수 있다. 그러나, 스마트폰을 중계기로 활용한 인터넷 접속 역시, KTX 무선 인터넷처럼 데이터 처 리율의 심하게 변함을 확인할 수 있었다.

\subsection{WiBro - Wi-Fi 토폴로지}

$\mathrm{WiBro}$ 와 $\mathrm{Wi}-\mathrm{Fi}$ 로 구성된 토폴로지에서의 성능 측정은 각각 자동차와 지하철에서 수행하였다. 우선 서울지하철1)에 서 KT Wibro를 이용한 휴대형 무선공유기인 egg에 의한 처리율을 살펴보았다. 지하철에서의 평균 다운링크 처리율 과 업링크 처리율은 각각 $2799 \mathrm{Kbps}, 531 \mathrm{Kbps}$ 이고. (그림 8)

1) 서울지하철의 평균이동속도는 $44 \mathrm{~km} / \mathrm{h}$ 이다.

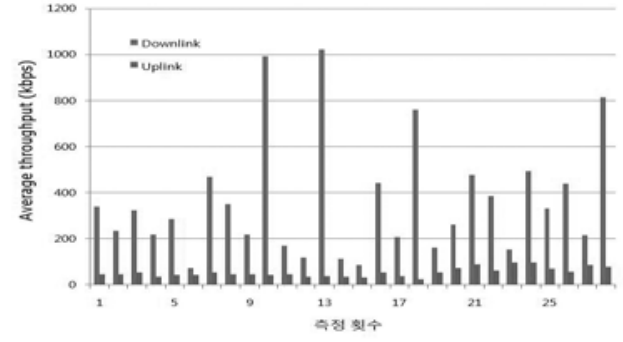

(그림 6) KTX에서 측정 결과

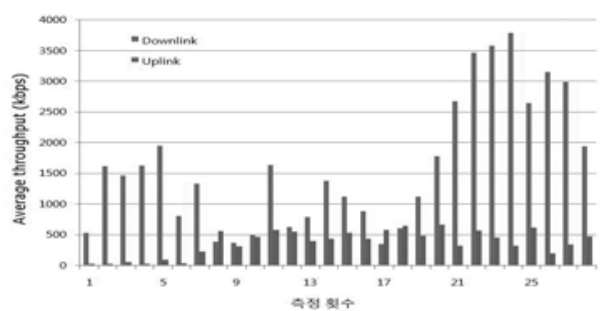

(그림 7) 스마트폰을 이용하여 지하철에서 측정 결과

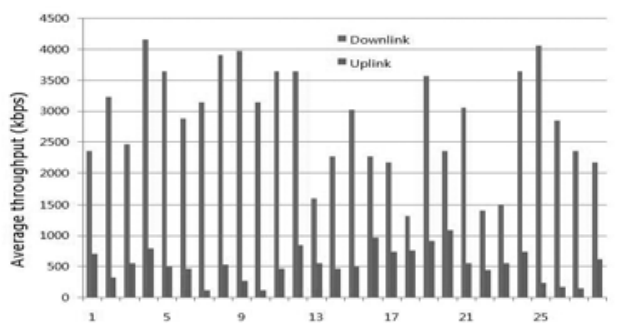

(그림 8) egg를 이용하여여 지치하철에서 측정 결과

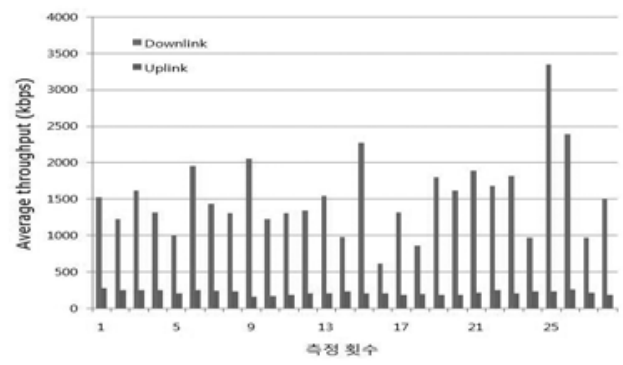

(그림 9) egg를 이용하여 자동차에서 측정 결과

은 지하철에서 다운링크와 업링크 처리율을 측정한 결과를 보여준다. 다운링크의 평균 처리율은 앞의 $\mathrm{HSDPA}-\mathrm{WiFi}$ 구 조에서의 평균 다운링크 처리율과 비교 하여 더 높고, 안정 적인 것을 볼 수 있다. 또한 업링크의 평균 처리율 역시 보 다 우수한 수준이었다.

(그림 9)는 동일한 토폴로지 환경을 이용하여 자동차에서 측정한 결과를 나타낸다. 이동 구간은 내부순환도로 (평균 $60 \mathrm{~km} / \mathrm{h}$ ) - 강변도로 (평균 $70 \mathrm{~km} / \mathrm{h}$ ) - 시내 - 경인고속도로 (평균 $80 \mathrm{~km} / \mathrm{h}$ ) 이었고, 시내를 제외한 구간은 모두 등속도 에서 실험을 진행하였다. 측정결과, 평균 다운링크 처리율은 $1530 \mathrm{Kbps}$ 이고 평균 업링크 처리율은 $210 \mathrm{Kbps}$ 이었으나, 이 것은 지하철에서 측정할 때보다 더 낮은 처리율이다. 지하 
철의 경우, 많은 수의 WiBro 중계기를 통해 신호 감쇄나 페 이딩 효과를 줄일 수 있지만, 자동차를 이용할 경우는 주변 에 장애물이 많이 존재하여 채널 상태가 더 불안정하기 때 문인 것으로 사료된다. 한편 최근, 정부에서는 고속도로에 더 많은 $\mathrm{WiBro}$ 중계기를 설치한다는 방침을 발표한 바 있 어 앞으로는 도로 환경에서도 보다 향상된 처리율을 얻을 수 있을 것으로 기대된다. 반면, 자동차의 속도를 변화시키 며 처리율을 측정한 결과 자동차의 속도는 처리율의 큰 영 향을 미치지 않는 것을 확인할 수 있었다.

지금까지 $\mathrm{KTX}$ 무선 $\mathrm{AP}$, 무선 공유기 (egg, 스마트폰)를 이용한 무선 인터넷의 다운링크/업링크 처리율에 대한 결과 를 살펴보았다. 그 결과, $\mathrm{HSDPA}-\mathrm{WiFi}$ 토폴로지는, $\mathrm{WiBro}$ 기반의 차량 네트워크와 달리, 실시간 멀티미디어 응용 프 로그램에 적합하지 않음을 확인할 수 있었다. $\mathrm{WiBro}-\mathrm{WiFi}$ 구조에 비해 $\mathrm{HSDPA}$ 기반의 차량 네트워크에서 더 낮은 처리율이 발생하는 원인은 차량 네트워크의 무선 인터넷을 지원하기 위한 WWAN-WLAN의 구조 때문이다. 첫째, WWAN-WLAN 구조는 서로 다른 이질적인 (heterogeneous) 네트워크가 구성된 것이다. 따라서 이 구조에서 지원할 수 있는 최대 전송 처리율은 WLAN과 WWAN이 지원하는 처 리율 중, 작은 값을 갖는 네트워크 (HSDPA)의 전송 처리율 을 따르는 것이다. 둘째, WWAN 링크는 WLAN으로 향하는 패킷과 $\mathrm{WLAN}$ 으부터 전달된 패킷이 모이는 병목지점이기 때문이다. 특히, KTX 무선인터넷의 경우, WLAN에 많은 사 용자가 존재하여 스마트폰의 테더링에 비해 낮은 다운링크 처리율을 보였다. 따라서 $\mathrm{WiFi}$ 기반의 차량 네트워크의 성능 향상을 위해서, 이용자의 수와 응용 프로그램의 요구 사항 등에 따르는 효율적인 자원 관리/할당 기법이 필요하다.

\section{4. 관련 연구}

최근 차량 네트워크에서 인터넷 접속을 향상시키기 위한 다양한 연구들이 진행되고 있다.

MIT에서는 Cabernet [12] 프로젝트를 통해 차량 네트워크에 서 새로운 형태의 컨텐츠 전달 프로토콜을 제안하였다. Cabernet에서, 차량 네트워크는 오픈 $\mathrm{AP}$ 를 통한 인터넷 접속을 가정하고 있으며, 성능 향상을 위해 QuickWiFi와 CTP (Cabernet Transport Protocol)을 제안하였다. QuickWiFi는 빠 른 속도로 이동하는 차량의 $\mathrm{AP}$ 접속 성능을 향상시키기 위하 여 데이터 링크 계층에서의 빠른 접속을 제안한 기법이다. 또 한 $\mathrm{CTP}$ 는, 기존의 $\mathrm{TCP}$ 가 차량 네트워크에서 적합하지 않기 때문에, 프록시 기반의 새로운 전송 계층 (transport layer) 프 로토콜이다. 이 외에, $\mathrm{ViFi}$ [13]의 경우 $\mathrm{VoIP}$ 와 같은 실시간 응 용 서비스에 초점을 맞추어 성능 개선 방안을 제안하고 있다.

한편 [1]과 [14]에서는 차량 네트워크에서의 인터넷 접속 성능에 관한 연구 결과를 보고하고 있다. [1]에서는 오픈
$\mathrm{Wi}-\mathrm{Fi} \mathrm{AP}$ 에서의 연결성과 처리율을 분석하기 위해서 차량 9 대의 이동 패턴을 232 일 동안 모니터한다. 그 결과 평균적인 연결 지속 시간은 약 24초였으며 처리율은 수십 $\mathrm{Kbps}$ 정도 임을 알 수 있었다. 또한 속도가 $70 \mathrm{Km} / \mathrm{h}$ 이상이 되는 경우 도로 주변에 오픈 $\mathrm{AP}$ 가 충분히 배치되어 있지 않기 때문에 $\mathrm{AP}$ 연결이 쉽지 않음을 보여주고 있다. [13]에서는 차량의 속도가 빠른 경우 $\mathrm{Wi}-\mathrm{Fi}$ 접속 처리율은 지원 가능한 처리율 의 절반 수준임을 보여주고 있다. 그리고 이러한 처리율 향상 을 위해서 네트워크 프로토콜 상에서의 연결 지연 시간을 단 축시키는 기법과 전송률을 조정하는 기법을 제안하고 있다.

이 외에 WLAN이 아닌, IEEE $803.16 \mathrm{j}$ 와 같이 WWAN의 결합된 구조에 대한 연구가, 2005년 7월 IEEE 802.16 MMR (Mobile Multi-hop Relay) 연구가 시작 된 이래로 [9], 2006 년 3월 IEEE 802.16j Relay 프로젝트 그룹이 구성되어 진행 되었다 [10]. 802.16j는 기지국의 영역 밖에 있는 음영지역에 데이터 전달을 위해, 중간에 중계기를 두어 신호 전달을 가 능하게 하기 위한 표준이다. 또한 기지국 영역 내에 있는 단말에 대해서도 중계기를 통한 고품질의 경로를 설정할 수 도 있다. 하지만 $802.16 \mathrm{j}$ 는, $\mathrm{KTX}$ 무선 인터넷과 $\mathrm{egg}$, 스마트 폰 테더링처럼 WWAN과 WLAN이 결합한 구조와 달리, 현 재 서비스가 널리 이루어지지 않고 있다. 또한 대부분의 모 바일 인터넷 기기에 $\mathrm{Wi}-\mathrm{Fi}$ 가 장착된 것에 비해, $802.16 \mathrm{j}$ 은 무선 인터넷 접속을 위해 해당 인터페이스를 지원하는 기기 를 따로 구입해야 한다. 따라서 사용자들은 차량 내에서, $802.16 \mathrm{j}$ 처럼 WWAN을 사용한 직접적인 무선 접속이 아닌 $\mathrm{Wi}-\mathrm{Fi}$ 를 이용한 WLAN-WWAN 방식의 인터넷 접속을 더 선호할 것이다.

이와 같이 차량 네트워크와 관련하여 다양한 연구가 진행 되고 있지만, $\mathrm{Wi}-\mathrm{Fi}$ 를 이용한 WWAN-WLAN 구조가 차량 네트워크의 대표적인 구조가 될 것으로 예상된다. 그러나 이 구조에서 실제적인 성능 측정 연구는 보고된 바 없기 때 문에, 본 연구는 기존 연구와의 차별성을 가진다.

\section{5. 결 론}

본 논문에서는 WWAN과 WLAN이 결합된 차량 네트워 크에서 $\mathrm{Wi}-\mathrm{Fi}$ 를 통한 인터넷 접속의 성능을 측정하고 분석 하였다. <표 $3>$ 은 측정된 처리율을 요약한 것이다. 표 3 에 서 보는 것처럼, 업링크 처리율이 매우 낮아 양방향 멀티미 디어 응용 및 사용자 파일 전송 (이메일을 통한 파일 전송, $\mathrm{ftp}$ 를 이용한 파일 업로드 등등)에 적합하지 않는 HSPDA$\mathrm{WiFi}$ 와 달리, $\mathrm{WiBro}-\mathrm{WiFi}$ 구조는 보다 안정적인 다운링크/ 업링크 데이터 전송률을 제공할 수 있음을 확인하였다.

또한 KTX처럼 WLAN에 사용자가 많이 존재할 경우, WWAN의 병목지점으로 인해 업링크와 다운링크 처리율이 현저히 낮아진다. 따라서 차량 네트워크에서 인터넷 사용자 
에게 일정 수준 이상의 $\mathrm{QoS}$ 를 지원하기 위해, $\mathrm{WLAN}$ 의 자 원을 효율적으로 사용하게 하기 위한 새로운 자원관리 기법 이 필요하다. 이 때, 차량 네트워크를 위한 새로운 자원관리 기법은 이용자의 차량 네트워크만이 가지는 고유한 특성을 고려하여 설계되어야 한다. 예를 들어, $\mathrm{KTX}$ 와 시내버스와 같은 대중교통은 주행 경로가 항상 일정하나, 시내버스는 $\mathrm{KTX}$ 에 비해 승객들의 승, 하차 이벤트가 자주 발생하고, 평균 차량 탑승시간은 짧다. 이렇듯, 차량 네트워크가 가진 고유한 특성을 고려하여 제안된 이동성 인지 호 수락 제어 알고리즘 [15]처럼, 차량 네트워크의 무선자원 관리를 위한 연구는 향후 매우 흥미로운 연구주제가 될 것이다.

〈표 3〉 측정 결과

\begin{tabular}{|c|c|c|c|c|}
\hline & $\begin{array}{c}\mathrm{KTX} \\
(\mathrm{Kbps})\end{array}$ & $\begin{array}{c}\text { 지하철 } \\
(\mathrm{HSDPA}) \\
(\mathrm{Kbps})\end{array}$ & $\begin{array}{c}\text { 지하철 } \\
\text { (Wibro) } \\
\text { (Kbps) }\end{array}$ & $\begin{array}{c}\text { 자동차 } \\
\text { (Kbps) }\end{array}$ \\
\hline 최소 다운링크 처리율 & 70.6 & 347 & 1100 & 612 \\
\hline 최대 다운링크 처리율 & 1030 & 3790 & 4100 & 3350 \\
\hline 평균 다운링크 처리율 & 363.9 & 1610 & 2799 & 1530 \\
\hline 최소 업링크 처리율 & 22.5 & 24 & 111 & 162 \\
\hline 최대 업링크 처리율 & 97 & 666 & 1080 & 269 \\
\hline 평균 업링크 처리율 & 52.5 & 372 & 531.3 & 209.7 \\
\hline
\end{tabular}

\section{참 고 문 헌}

[1] V. Bychkovsky, B. Hull, A. Miu, H. Balakrishnan, and S. Madden, "A Measurement Study of Vehicular Internet Access using In Situ Wi-Fi Networks," in Proc. ACM MobiCom 2006, September 2006.

[2] H. Petander, E. Perera, K. Lan, and A. Seneviratne, "Measuring and Improving the Performance of Network Mobility Management in IPv6 Networks," IEEE Journal on Selected Areas in Communications, Vol .24, no. 9, pp. 1671-1681, September 2006.

[3] S. Pack, H. Rutagemwa, X. Shen, J. Mark, and L. Cai, "Performance Analysis of Mobile Hotspots with Heterogeneous Wireless Links," IEEE Transactions on Wireless Communications, vol. 6, no. 10, pp. 3717-3727, October 2007.

[4] http://wmwifirouter.com/.

[5] http://speed.nia.or.kr/.

[6] http://en.wikipedia.org/wiki/Iperf.

[7] X. Liu, A. Sheth, M. Kaminsky, K. Papagiannaki, S. Seshan, and P. Steenkiste, "DIRC: Increasing Indoor Wireless Capacity Using Directional Antennas," in Proc. ACM SIGCOMM 2009, August, 2009.

[8] J. Choi, M. Jain, M. A. Kazandjieva, and P. Levis, "Granting Silence to Avoid Wireless Collisions," in Proc. IEEE ICNP 2010, October, 2010.

[9] http://www.ieee802.org/16/sg/mmr/.

[10] http://wirelessman.org/relay/.

[11] 3GPP TR 23.203 v8.2.0, "Policy and charging control architecture," 2008.

[12] J. Eriksson, H. Balakrishnan, and S. Madden, "Cabernet: Vehicular Content Delivery Using WiFi," in Proc. ACM Mobicom 2008, September 2008.

[13] A. Balasubramanian, R. Mahajan, A. Venkataramani, B. N. Levine, and J. Zahorjan, "Interactive WiFi Connectivity for Moving Vehicles," in Proc. ACM SIGCOMM 2008, August 2008.

[14] V. Bychkovsky, B. Hull, A. Miu, H. Balakrishnan, and S. Madden, "Vehicular Opportunistic Communication Under the Microscope," in Proc. ACM MobiSys 2007, June 2007.

[15] Y. Kim, S. Pack, and W. Lee, "Mobility-Aware Call Admission Control Algorithm in Vehicular WiFi Networks," in Proc. IEEE GLOBECOM 2010, December 2010.
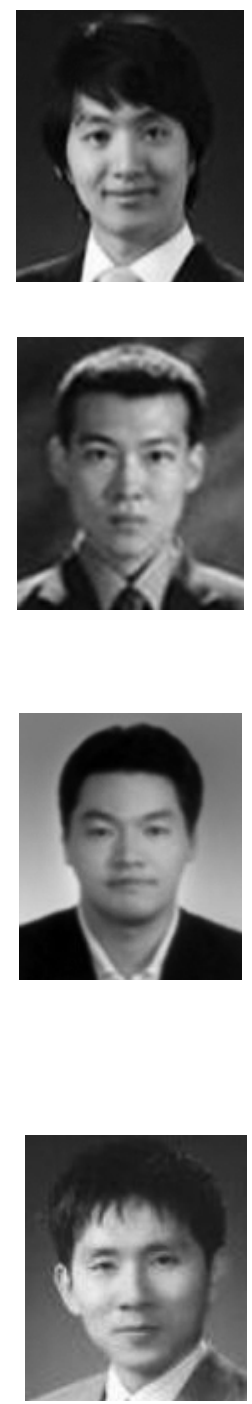

\section{김 원 중}

e-mail : abcxxxx@korea.ac.kr 2010년 고려대학교 전기전자전파공학부(학사) 2010년 현 재 고려대학교 전기전자전파 공학부 석사과정

관심분야: 차량 네트워크, 이동/무선 네트워크 등

\section{김 영 현}

e-mail : younghyun_kim@korea.ac.kr 2005년 숭실대학교 컴퓨터학부(학사) 2007년 숭실대학교 컴퓨터학과(석사) 2008년 현 재 고려대학교 전기전자전파 공학부 박사과정

관심분야: 무선 이동 네트워크, 네트워크 보안

윤 주 상

e-mail : jsyoun@deu.ac.kr

2001년 고려대학교 전기컴퓨터공학부(학사) 2003년 고려대학교 전자공학과(석사) 2008년 고려대학교 전자컴퓨터공학과(박사) 2008년 현 재 동의대학교 멀티미디어 공학과 조교수 관심분야: 애드혹/센서 네트워크, 멀티 네트워킹

\section{백 상 헌}

e-mail:shpack@korea.ac.kr

2000년 서울대학교 컴퓨터공학부(학사)

2005년 서울대학교 전기컴퓨터공학부(박사)

2007년 현 재 고려대학교 전기전자전파 공학부 조교수

관심분야: 무선 이동 네트워크, 차량 네트워크 